\title{
Embarazo de la Psicoterapeuta y Relación Psicoterapéutica: Cuando Yo fui Nosotros ${ }^{1}$
}

\author{
Anabela Amaral Rosando \\ PsiRelacional, Lisboa, Portugal
}

El presente trabajo busca evidenciar el impacto de las alteraciones al setting en la relación psicoterapéutica, especialmente en el momento del embarazo de la psicoterapeuta. El embarazo se presenta como la introducción del otro, de forma presente y efectiva, en la relación que era, hasta entonces, dual. De este modo, el embarazo de la psicoterapeuta se describe como un factor que propicia la aparición de sentimientos y conflictos, conscientes e inconscientes, tanto para el paciente como para la psicoterapeuta, modelando el curso del proceso psicoterapéutico.

Palabras clave: Relación psicoterapéutica, Embarazo de la psicoterapeuta, Setting, Psicoterapia.

The present work tries to show the action of alterations to the setting in the psychotherapeutic relation, namely during the pregnancy of the psychotherapist. Pregnancy is presented as the introduction of the other, in a present and effective way, in the relationship that was, until then, dual. In this way, the psychotherapist's pregnancy is described as a factor that fosters the appearance of conscious and unconscious feelings and conflicts, both for the patient and for the psychotherapist, modelling the course of the psychotherapeutic process.

Key Words: Psychotherapeutic relationship, Pregnancy psychotherapist, Setting, Psychotherapy. English Title: Pregnancy of the Psychotherapist and Psychotherapeutic Relationship:

When I was We

\section{Cita bibliográfica / Reference citation:}

Rosando, Anabela Amaral. (2019). Embarazo de la Psicoterapeuta y Relación Psicoterapéutica: Cuando Yo fui Nosotros. Clínica e Investigación Relacional, 13 (1): 134-139. [ISSN 1988-2939]

[Recuperado de www.ceir.info ] DOI: 10.21110/19882939.2019.130109

\footnotetext{
${ }^{1}$ Trabajo presentado en las /l Jornadas de Psicanálise Relacional. Fac. de Psicologia, Lisboa, Mayo de 2018. Versión castellana de la autora, con leves modificaciones editoriales de la redacción de CelR. ªnabela.rosando@gmail.com
} autorización expresa. Este material es para uso científico y profesional exclusivamente y puede contener información clínica sensible. Los editores no se responsabilizan de los contenidos de los autores. Dirigir las consultas sobre derechos y autorizaciones a ceir@psicoterapiarelacional.es 


\section{Cuando Yo fui Nosotros}

Yo fui Nosotros cuando aún eras un deseo y los deseos no quedan fuera del consultorio, esperando a la puerta; entran, se sientan y se hacen presentes en aquello que pensamos y en aquello que sentimos, en cada una de nuestras palabras, en las palabras de los pacientes, en todas las acciones. Recuerdo a André, un niño de 9 años al que acompaño en psicoterapia desde hace cuatros años, diciéndome en medio de un juego, cuando aún eras un deseo: "Sé que estás embarazándote" - ¿Embarazándome? ¿Qué es eso de estar embarazándose?" - "Claro, estás embarazándote, ya sabes". Y recuerdo quedarme pensando en qué habría espoleado aquel comentario... ¿qué fantasía me estaba mostrando? Hoy, sé que vino de la presencia de mi deseo.

Mi embarazo condicionó el setting antes incluso de que otra vida naciese en mí; la condicionó antes incluso de haber cobrado conciencia de mi deseo.

Después llegaste: mi deseo era ahora real, jexistías! Existías y crecías dentro de mí; ganabas forma en mi cuerpo, te daba forma en mi mente. $Y$ Yo ¡fuimos Nosotros! Creo que los cambios internos del psicoterapeuta pueden llegar a modelar la sesión de forma más profunda que los cambios físicos. La concreción de este deseo, quedarme embarazada, me trajo una sensación de plenitud; me sentía más mujer, impregnada de vida, activa, más vinculada, más conectada. Más en conexión conmigo misma, más en conexión con mis pacientes. Justo al inicio del embarazo, una paciente a la que acompaño desde hace dos años y medio, María, me dijo: "Hoy está Usted muy guapa. No digo que el resto de los días no lo esté, pero hoy tiene algo distinto; no sé, no le sabría decir". De hecho, estar embarazada de mis hijos me hizo sentir siempre mucho más guapa.

Ahora, ¡Yo éramos Nosotros! En mi mente Tú, Yo, yo madre, mi madre, yo hija, yo mujer... el embarazo introduce la necesidad de cambio; cambio y reestructuración en los diferentes papeles que desempeñamos, como mujer, como madre, como profesional. Introduce también la necesidad de lidiar con el miedo: el miedo a peligros reales o imaginarios. ¿Qué espacio queda, dentro de mí, para el otro?

En las primeras semanas del embarazo todos los martes acababa cansada. Me sentía llena de energía, llena de ganas de trabajar, tenía una sensación permanente de estar en más sintonía, conmigo, con los pacientes; sin embargo, los martes me invadía un cansancio, un cierto malestar, que me dejaban preocupada y me hacían plantearme que quizás debía aflojar el ritmo. Fue cuando tomé consciencia de mi dificultad en las sesiones con niños. En aquella altura, los martes sólo recibía niños. Trabajar con niños es, sin duda, diferente a 
hacerlo con adultos; requiere, entre otras cosas, de una disponibilidad física. Nos priva del confort y protección de nuestro sofá. Se nos invita a jugar, nuestro cuerpo juega y muchas veces es usado para jugar. La experiencia me dice que en el trabajo con niños sentimientos como la agresividad, el enfado, la rabia, la envidia y los celos no se manifiestan sólo en sus dibujos, sino que pueden y son muchas veces dirigidos al cuerpo; me acuerdo de Tiago, un niño de 10 años, diciendo "¿Vamos a hacer como si tuvieras un alien en la tripa y yo te lo tengo que arrancar?" Tal vez en ese momento yo estuviera ante un conflicto: si por un lado mi cuerpo era un aliado para el desarrollo de mi trabajo, por otro mi cuerpo tenía la función primordial de alimentar y proteger a mi bebé. Mi conflicto no se acabó al tomar conciencia de él, acabó cuando dejaste de existir en secreto. Al final del primer trimestre desaparecieron todos los cansancios y molestias de los martes. Estaba más segura, más tranquila, y también sentía que podía volver a ser más espontánea y auténtica en la relación con mis pacientes.

La barriga crece, te mueves, tus movimientos reclaman mi atención y a partir de ese momento ¡estás siempre conmigo! Reaccionas a lo que siento y tengo, incluso, la fantasía de que me alertaste de mi contratransferencia en algunos momentos.

La barriga crece, la presencia del bebé comienza a ser evidente y la psicoterapia que hasta entonces se hacía a dos, pasa a ser a tres.

Surge la duda: ¿comunicar o no comunicar el embarazo al paciente?

Hay distintas posiciones sobre esta cuestión. Mi opción fue comunicarlo sólo a una paciente: a aquella paciente a la que recibí cuando ya estaba embarazada, se lo comuniqué en el mismo momento en el que establecí el contrato terapéutico. Curiosamente, fue, de entre los pacientes adultos, la que se mostró más molesta y reveló un mayor sentimiento de abandono durante el periodo en que estuve ausente. Con los restantes, esperé a que de forma natural se dieran cuenta y reaccionasen a la nueva situación.

La percepción del embarazo sucedió de forma particular y específica con cada uno de los pacientes. Unos, a pesar de las evidencias físicas, no lo veían; otros lo comentaban de forma bastante cariñosa; otros mostraban mucha curiosidad en relación con el embarazo, en relación a mí. Pero al margen de las reacciones manifestadas, era evidente que este acontecimiento interfería en la relación y en consecuencia en el transcurso de la psicoterapia con cada uno de ellos. Tu presencia allí trajo a la relación terapéutica, de forma clara, reacciones de miedo a la perdida, miedo al abandono, rivalidad entre hermanos, conflictos con la identificación materna y envidia. Creo que algunos de estos conflictos, fantasías y deseos no se hubiesen hecho notar de forma tan clara, y en algunos casos tan rápidamente, 
de no haber sido por la imposición del embarazo en el setting.

Cuando estaba embarazada de siete meses, una paciente a la que acompaño en psicoterapia desde hace siete años con una frecuencia de dos sesiones por semana, me dijo al inicio de una sesión: "Anabela, ¿está Usted embarazada otra vez? Yo ya había notado que la veía así como más llenita, pero hoy me parecía que esa barriga era algo más que una buena fabada". En las siguientes semanas planteó, con satisfacción, la posibilidad de estar también embarazada. Cuando preparé la interrupción de la psicoterapia manifestó "Sí, no hay problema, perfecto, como la vez anterior. Hasta le confieso que me va a venir bien. La terapia dos veces por semana es demasiado: salgo que no tengo cabeza para las cosas del trabajo". Algún tiempo después de haber retomado la psicoterapia dijo "No quiero para nada tener hijos. Hasta me parece de una cierta inconsciencia, estando el mundo como está. No es que las otras personas no puedan tener ese deseo, es que yo no lo tengo, ¿Para qué? Ya he visto cómo es el final. ¿Qué sentido tiene la vida si es para acabar así?"

Otra paciente, frente a mi embarazo, manifestó un gran deseo de proximidad y miedo al abandono. Hizo varias preguntas sobre el embarazo y en la sesión siguiente comenzó a presentar la asimetría con tristeza...." Hay tantas cosas que no sé y me gustaría saber sobre Usted, y que, de todas formas, Usted no me va a decir porque no somos amigas"... "Si por cualquier motivo dejase de venir, Usted no me va a llamar para quedar para un café o algo así. Nuestra relación es sólo de aquí. Es eso lo que me da pena" "Usted tiene su vida". Cuando se acercó el final del embarazo, María comenzó a llegar con 15 minutos de adelanto, tocaba incesantemente el timbre y se mostraba muy molesta porque no le abriese de inmediato.

La paciente a la que recibí cuando ya estaba embarazada y a la que indiqué desde el inicio en el contrato terapéutico en qué periodo iba a estar ausente, en el último mes antes de la interrupción de la psicoterapia iniciaba las sesiones diciendo: "Hay varios temas de los que aún no he hablado". Negó la dificultad que estaba sintiendo con la separación y cuando regresé refirió, muy emocionada, que se había sentido sola, mostrándose muy molesta con el hecho de haberse sentido abandonada, desprotegida.

Con los niños fueron los padres los que hicieron los primeros comentarios y mostraron mayor curiosidad. "¿De cuántos meses está?", "¿Va todo bien?", "¿Ya sabe si es niño o niña?", "¿Es su primer hijo?", "¿Ya tiene nombre?" o "¿Y para cuándo?" Una de estas preguntas por parte de la madre de Tiago al final de una sesión, le hizo reaccionar con sorpresa "¿Estás embarazada? ¿Cómo?" En las siguientes sesiones se mostró inquieto por saber si mi bebé era una niña. "Quizás te guste más jugar con niñas..." Es relevante que Tiago sea el mayor de cuatro hijos, dos de la madre y dos del padre, tres chicos y una chica, por ese orden, y que 
después del nacimiento de la hermana, comenzó a sentir al padre menos disponible para él, habiendo llegado a decir que todo sería distinto si la hermana no hubiese nacido. En ese caso -la experiencia vivida en la relación terapéutica poco habrá contribuido a cambiar su sentir-, la madre decidió interrumpir la psicoterapia durante mi baja maternal.

Con André, aquel que ya sentía que Yo éramos Nosotros cuando aún eras un deseo, también fue el padre el que hizo la revelación. Un día al inicio de la sesión, al despedirse de su hijo dijo: "Hasta luego, y atento a lo que te dije en casa, mucho cuidado con lo que hay aqui" estira la mano para tocar mi barriga -lo que me hace dar un paso atrás-, y continua "¿sabes lo que hay aqui?" André respondió sin mirar, desde donde estaba, en el suelo montando trenes con aire indiferente "ya lo sé, es un bebé". En esa sesión no quiso hablar de eso, más tarde me preguntó por qué "tú ya tenías un hijo, ¿por qué vas a tener otro?" En otra sesión, ya más cerca del fin del embarazo, cambió todos los muebles de la sala tratando de hacer una inversión perfecta de la disposición de todo el mobiliario. Fue un periodo especialmente difícil para André, con sucesos graves en el colegio, agresión a profesores, a empleados y automutilaciones. Ya hacia el final del embarazo escribió una definición de sonreír en el ámbito de un trabajo realizado en los centros educativos dentro del proyecto "Nariz Roja": "Sonreír es... un pozo de tristeza, es una fuente de desilusión y también una lluvia con tormenta".

Con Lucas también fue la madre la que introdujo el tema, nada intrusiva y siempre con comentarios muy cariñosos. Peo Lucas nunca aceptó hablar sobre el hecho de que yo estuviese embarazada, ni sobre la interrupción temporal del proceso terapéutico que se avecinaba. En una sesión en que saqué el tema de forma más directa dijo "no quiero hablar de eso. No quiero ni pensar en ello" -"Tienes miedo?" "A veces pasan cosas malas, con los bebés y las madres" -Todo va a ir bien "Calla, no hables de eso, no quiero pensar en ello. Si yo no pienso en ello todo va a ir bien".

Sentí que la pérdida de neutralidad, con la introducción de mi vida personal, afectó bastante al setting, y de forma más intensa a la psicoterapia con niños; no sólo por la reactivación de conflictos, fantasías, deseos, sino también porque sentí que en algunos casos, estaba siendo utilizada por los padres como ataque a la relación terapéutica. En el caso de André, fue frecuente oír a la madre decir al final de las sesiones: "anda hijo, vamos, que Anabela tiene que ir a su casa a descansar por el bebé, y está su hijo esperándola".

Cuando Yo fuimos Nosotros, fue así y además jtodo aquello que yo no vi!

\section{REFERENCIAS}


Coimbra de Matos, A. (2002). A contratransferência como resistência do analista e como material do processo analítico. In Psicanálise e Psicoterapia Psicanalítica (29-48). Lisboa: Climepsi Editores.

Coimbra de Matos, A. (2004). Vinculação e ligação na prática clínica. In Saúde Mental. Lisboa: Climepsi Editores.

Klein, M. (1991). Inveja e Gratidão e Outros Trabalhos 1946-1963. Rio de Janeiro: Imago.

Luz, A. B.; Kaidann, C. E. y Dal Zot, J. S.D. (2006). Contratransferência e os factores da vida pessoal do psicoterapeuta e/ou psicanalista. In J. Zaslavsky; M. J. P. dos Santos (Eds.) Contratransferência - Teoria e Prática Clínica (269-289). Porto Alegre: Artmed.

McWilliams, N. (2006). Psicoterapia Psicanalítica. Guia para Terapeutas. Lisboa: Climepsi Editores.

Norcross, J. C. (2000). Psychotherapist Self-Care Practioner-Tested, Research-Informed Strategies. Profissional Psychology: Research and Pratice, 31 (6), 710-713.

Tonon, C. B.; Romani, P. F. y Grossi, R. (2012). A Gravidez da Terapeuta e seus Reflexos no Processo Psicoterápico. Psicologia: Teoria e pesquisa, 28 (1), $87-92$.

Winnicott, D. W. (1975). O Brincar \& a Realidade. Rio de Janeiro: Imago.

Winnicott, D. W. (2000). Da Pediatria à Psicanálise Obras escolhidas. Rio de Janeiro: Imago.

Original recibido con fecha: 26/9/2018 Revisado: 15/03/2019 Aceptado: 30/03/2019

En este mismo número de CelR se publica la versión original portuguesa de este trabajo. 